\title{
Feminist Philosophy Quarterly
}

Volume 4| Issue 2

Article 1

2018

Burning it in? Nietzsche, Gender, and Externalized Memory

Marie Draz

San Diego State University, mdraz@mail.sdsu.edu 


\title{
Burning It In? Nietzsche, Gender, and Externalized Memory ${ }^{1}$ Marie Draz, San Diego State University
}

\begin{abstract}
In this article, I extend the feminist use of Friedrich Nietzsche's account of memory and forgetting to consider the contemporary externalization of memory foregrounded by transgender experience. Nietzsche's On the Genealogy of Morals argues that memory is "burnt in" to the forgetful body as a necessary part of subject-formation and the requirements of a social order. Feminist philosophers have employed Nietzsche's account to illuminate how gender, as memory, becomes embodied. While the account of the "burnt in" repetitions of gender allows us to theorize processes of embodied identity on an individual level, analyzing gender today requires also accounting for how gender is externalized. I take up this question through the specific examples of identity documents and sex-segregated bathrooms. Returning to Nietzsche's call to practice a resistant forgetting, I conclude by exploring the distinct strategies required to disrupt externalized memory. These strategies include contesting the use of past gender assignments in data collection and rewriting architectural reminders of gender.
\end{abstract}

Keywords: Nietzsche, memory, forgetting, gender, feminism, transgender, identity documents, sex-segregated bathrooms

\footnotetext{
"Feminist work is often memory work." - Sara Ahmed, Living a Feminist Life
}

In Chicago's South Loop neighborhood, one of the world's largest data centers spans 1.1 million square feet. The site is one of many so-called data farms that have cropped up alongside the internet, as the relentless collection of data

\footnotetext{
${ }^{1}$ The research for this essay was in part supported by a faculty research grant from the College of Arts and Letters at San Diego State University. I would also like to acknowledge the participants of the Southwest Seminar in Continental Philosophy and the Nietzsche \& Critical Social Theory Conference for their helpful comments on an earlier version of this project. Finally, I would like to thank Feminist Philosophy Quarterly's anonymous reviewers for their insightful feedback.
} 
through massive online servers has become big business. As the term "farming" suggests, this data gathering is commonly described with natural metaphors: data pools and streams, ebbs and flow, leaks and clouds (Lupton 2013). In a talk at a conference on big data, web developer Maciej Ceglowski argues against such "bucolic terminology" in favor of imagining big data as waste product. While the massive amount of collected data seems innocuous and likely to be forgotten, Ceglowski argues that its persistence actually rivals that of nuclear waste; given that "the whole point of having a data lake is you can just chuck things in there and go fishing for patterns later," Ceglowski cautions that the lifespan of data is "far longer than the institutions we could build to guard it" (2015). While it is tempting to think that much of this data will be forgotten, through the sheer vastness of what is collected if nothing else, it is also crucial to acknowledge its persistence as memory.

The unpredictable effects of such massive data collection provide a stark reminder of the complexity of thinking about memory and forgetting today. From a philosophical standpoint, one of the most generative accounts of memory and forgetting arguably appears in Nietzsche's On the Genealogy of Morals. Here, memory is "burnt in" to the body as a necessary part of subject-formation and civilization. Feminist philosophers have employed Nietzsche's account to illuminate how gender, as memory, becomes embodied. In this essay, I extend and complicate this feminist Nietzschean account by examining the contemporary externalization of memory. Keeping the thread of gender as memory, I explore two examples of the externalization of memory foregrounded by trans experience ${ }^{2}$ : identity documents and sex-segregated bathrooms. Finally, I argue that paying attention to the externalization of gender as memory today requires taking seriously Nietzsche's call to practice a resistant forgetting.

\section{Memory and Forgetting in Nietzsche's On the Genealogy of Morals}

In the second essay of On the Genealogy of Morals, Nietzsche locates the emergence of culture in the ability to make promises. To ensure that a promise is kept, he writes, a memory of that promise must be created: "That this problem has been solved to a large extent must seem all the more remarkable to anyone who appreciates the strength of the opposing force, that of forgetfulness" (Nietzsche

\footnotetext{
2 Throughout the essay, I use trans and transgender to indicate a wide variety of ways that people move away from the gender assigned at birth. At a few points, I link trans with gender nonconforming in order to emphasize the many paths of departure from gendered assignments and expectations. I emphasize that these are political terms and thus open to contestation and renegotiation. For more on how these terms developed in the context of the US and should not be hastily universalized, see Stryker 2008.
} 
$1989,57)$. Acknowledging that forgetfulness is usually cast in a negative light, Nietzsche positions it instead as an active and creative force that allows one to "close the doors and windows of consciousness for a time," enjoy "a little quietness," and "make room for new things" (57-58). However, while forgetfulness can be a sign of health, or a way to remain open to forces at work in the present, it must be revoked when one needs to remember a promised future. As Rosalyn Diprose $(2002,22)$ puts it, "The modern moral subject, the individual who is responsible for his or her acts enough to enter social contracts, requires a faculty that opposes forgetting-memory."

The active desire to remember is not itself the problem for Nietzsche. To the contrary, he positively marks the ability to enact what one promises as a sign of a sovereign individual; this sovereignty is held up as the "ripest fruit" of this process, or as at least one possible outcome of such memory work (Nietzsche 1989, 59). Instead of focusing on memory writ large, he locates the problem in the calculability and predictability that so easily results from this social memory machine. In establishing this interpretation of memory and forgetting in Nietzsche's work, Diprose writes that he is describing a "particular kind of memory, a memory that unifies a selection of activities, events, experiences, and effects so that they belong to one person" (22). For Nietzsche, it is crucial that this unifying narrative work of memory operates in service to a promised future (i.e., how we promise to act, what we will or will not allow to happen), and that this focus in turn all too easily safeguards sameness. This tightly wound temporal loop guarantees that what is to come will be a continuation of what has been. Through adhering to a promised future, a chain of inevitability is forged in the present. This, Nietzsche (1989) tells us, is the "long story" of how humans become "like among like" through a shared (and enforced) allegiance to a particular future (58-59).

One of the most intriguing aspects of this story is Nietzsche's claim that this memory is instituted through bodily pain, or the "mnemotechnics of pain" (61). Reflecting on the counteracting force of forgetfulness, Nietzsche argues that punishment is one way that memories are "burnt into" the body. Bodily pain buries the memory of the law inside. The embodied memory of punishment compels one to forestall future harm through a promised adherence to a social order. These techniques of punishment in turn carry social norms and values. As Nietzsche puts it, "With the aid of such images and procedures one finally remembers five or six 'I will not's,' in regard to which one had given one's promise so as to participate in the advantages of society" (62). Corporeal punishment forges a connection between the forgetful human and the legal subject, thereby creating a subject capable of linking a past promise with a future self. Given Nietzsche's genealogical coupling of guilt [Schuld] and debt [Schulden], Kristen Brown (2006) emphasizes that the emergence of a unified subject (a subject capable of linking a past promise with a future self) 
also halts the movement by which one's guilt or debt can be resolved or forgotten. Through the burning in of punishment, the subject is therefore made permanently guilty-in other words, the subject is made to remember.

After a long list of various corporeal forms of punishment ("stoning . . . breaking on the wheel . . . boiling the criminal in oil or wine" and so on [Nietzsche $1989,62])$, Nietzsche states that it is by taking refuge in the interiority of a memory that one is able to promise a future, or the "five or six 'I will not's'" (62). Through punishment, the subject both takes responsibility for past actions and forestalls future harm by anticipating the possible results of actions. As social promises grow stronger, the need for overt reminders lessens; your body remembers for you. The whole bloody, bodily process of instituting memory therefore only comes to a "sort of end" with the internalization of a consciousness that remembers. " "The severity of the penal code," Nietzsche writes, "provides an especially significant measure of the degree of effort needed to overcome forgetfulness and to impose a few primitive demands of social existence as present realities upon these slaves of momentary affect and desire" (61). Forgetfulness becomes a sign that one has not properly internalized the demands of the social and political order.

\section{Gender as Internalized Memory}

While feminist philosophers have questioned Nietzsche's account for its focus on, among other things, the primacy of aggression in the formation of the subject (Butler 2008; Diprose 2002), his work has remained a generative way for feminist philosophers to examine "a subject who internalizes the law" (Butler 2008, 15). ${ }^{4}$ Insofar as this subject is formed through the unification of actions across time, these learned expectations calcify in the habitual body; bodily memories are formed. As Michel Foucault (1977) develops through the concept of disciplinary power, the success of this political use of the body is due at least in part to the belief that the body is impervious to power. As such, it remains a powerful hiding place for social and political norms. In her work on Nietzsche, gender, and embodiment,

\footnotetext{
${ }^{3}$ While Nietzsche refers to a "consciousness" that remembers, his overall critique of the mind/body split invites the feminist reading of this memory through the gendered body, to which I turn below.

${ }^{4}$ As Kelly Oliver and Marilyn Pearsall (1998) write in their introduction to Feminist Interpretations of Nietzsche, feminist writing on Nietzsche generally falls into two camps. The first focuses on Nietzsche's comments about women and femininity, while the second asks how we might use Nietzsche's work to ask our own questions about gender. I locate my work here in the second of these camps without claiming to answer the question of whether these camps are or should be disconnected. For more on Nietzsche's use of women and femininity, see also Oliver (1995).
} 
Elizabeth Grosz $(1994,132)$ writes, "It is almost as if the skin itself served as a notebook, a reminder of what was not allowed to be forgotten ... the 'unforgettable' is etched on the body itself." Across its many different iterations, feminist theory has taken up the question of how the gendered requirements of a social and political order are "burnt in" to one's body.

In one of the more well-known examples of this line of thought, Judith Butler examines the minefield of punishment and reward that shapes how we navigate gender. Through the repetition of punished and rewarded acts in a highly regulated social frame, gender eventually "congeal[s]" into "the appearance of substance" or what we take to be "a natural sort of being" (Butler 1999, 43-44). Consider gendered practices of taking up space in public. As the popular "Men Taking Up Too Much Space on the Train" internet memes succinctly illustrate, the way one sits or stands in public often reflects intermeshed social identities, with gender operating as one salient factor. ${ }^{5}$ It is precisely because privileged ways of sitting, standing, or occupying space often feel quite natural that such projects seek to make us look again, or think twice about how our social identities have contributed to the ease with which we do or do not take up space. Butler draws on Nietzsche to explain that it is through precisely these kinds of bodily repetitions that we come to believe that there is a "doer behind the deed" or a gendered essence behind the gendered doing. By emphasizing the repetition that leads to the ease of a bodily habit, Butler articulates a framework in which the appearance of a stable, natural gender is actually constituted through the repetition of bodily acts over time. ${ }^{6}$

Following Nietzsche's invitation, this gender work can be understood as normalizing memory work. I mean this in two ways. First, these repetitive sanctions and rewards over lifetimes and generations create bodies that remember how to move, speak, take up space, adorn themselves, and so on. Through analyses of such bodily practices, feminist theorists have illustrated how habitual interpretations subsume new experiences (e.g., Ahmed 2006; Bartky 1990; Diprose 2002; and Young 2005). Bartky's (1990) classic account explores this punishment in terms of relationships: the failure to embody gender in particular ways may result in lost friendships, romantic relationships, and family connections. In Nietzschean language, gender becomes an embodied memory of a promise to a social and

\footnotetext{
${ }^{5}$ For more on the language of intermeshed social oppression as a model for intersectional theorizing that resists analogical thinking, see Lugones 2003. ${ }^{6}$ While I continue to use Nietzsche's language of "burning in" from Genealogy here, I acknowledge that both Foucault and Butler choose to develop this account along the lines of inscription, not internalization (Butler 1999; Foucault 1977). Due to my focus on how gender, as memory, is both taken into (or, in the model of inscription, inscribed on) and preserved outside the body, I do not belabor the distinction here.
} 
political order. To ensure the promise is kept, punishment (ranging from mundane shaming and social ostracizing to overt physical violence) is on deck. Normalizing forgetting also plays a role here: successfully embodying gender in this framework might be understood as the successful forgetting of this mundane and violent memory work.

Second, however, we might also consider resistance to the bodily congealing of gender to be a kind of memory work. In this resistant memory work, the emphasis is placed on remembering the repetitive acts and regulatory frames through which normative gender has been forged. For example, such work might involve recalling earlier moments in which one was explicitly rewarded or punished for taking up space in gendered ways. In turn, then, forgetting an expected or promised bodily repetition also serves as a source of resistance. At the level of bodily habits, this forgetting could entail working to alter the habitual ways one embodies gendered norms. This forgetting also requires memory work; it is by remembering what has been burnt in that resistant forgetting becomes possible. Through such work, we gain a better understanding of the promises that have been made. To think about forgetting in this way is, at least in part, to hear a Nietzschean echo of forgetting in the promise of genealogical approaches to gender. As Sara Ahmed (2006) puts it in Queer Phenomenology, "We don't know, as yet, what shape such a world might take ... when we no longer reproduce the lines we follow" (156). ${ }^{7}$ Or, in the language of Genealogy of Morals, "Every table of values, every 'thou shalt' ... requires first a physiological investigation" (Nietzsche 1989, 55, emphasis added).

\section{Gender as Externalized Memory}

In Memory Practices in the Sciences, Geoffrey Bowker (2005) describes memory as a property of infrastructures. The structures themselves, and not just the data they carry, store memory in ways that remain external to consciousness. Memory practices are the "range of practices (technical, formal, social) that . . . allow ... useful/interesting descriptions of the past to be carried forward into the future" (7). These practices, when exercised through structures such as classification systems and databases, preserve memory along particular lines (for example, according to certain keywords or markers) and allow the past to be recalled according to the demands of the present. In other words, memory practices help us to remember that which otherwise we may forget. "Memory is often, and wrongly,"

\footnotetext{
${ }^{7}$ This positive valuation of forgetting has also been explored in the context of what Lee Edelman (2007) calls reproductive futurism or Jack Halberstam (2011) discusses as the heteronormative mandate to focus on the future at all costs and to not lose one's way.
} 
Bowker writes, "conceived of as an act of consciousness and associated with what can be called to mind" (8). By turning to modes of remembering that have very little to do with what enters consciousness, but rather with how the past is preserved in structures all around us, Bowker emphasizes that "we are social and technical creatures who engage in a vast span of memory practices, from the entirely nonconscious to the hyperaware" (8).

In what follows, I extend the feminist use of Nietzsche's account of memory and forgetting to this question of externalized memory. Until this point, I have focused my discussion on how gender, as an internalized memory, serves to project the body into the future as a way to adhere to, or make a promise to, a social order. This account of the 'burnt in' repetitions of gender allows us to theorize processes of embodied identity on an individual level. To analyze gender today, however, it is necessary to account for how gender is externalized. This move not only implicates the interaction between individuals and external memory structures, but also complicates the question of where gender lives and how it is remembered. To elaborate the stakes of theorizing this distinction between internalized and externalized memory, I first turn to the question of what it means for memory to be preserved outside the body. I then turn to the question of what it means for the memory of gender to be externalized.

Many scholars have examined how memory practices take on a life of their own outside the body. In their respective projects, Adrian Forty and Susanne Küchler (1999) and Michel de Certeau (1984) both question how the externalization of memory may lead to its decay, shutting down its movement and dynamism. A related line of concern may be extended all the way back to the discussion in Plato's Phaedrus concerning whether the externalization of knowledge through techniques of writing will lessen the need to remember things on one's own. In these and related discussions, externalized memory is understood as something that can be contained and stored for retrieval. The question that emerges is how this storage of memory may release us from the responsibility of knowing things "by heart," or the potentially negative impact of memory being located elsewhere.

Against this view, others have argued that this focus on the danger of externalized memory too easily overlooks the "agency of things" and the "complex dynamics of remembering" that occur as external objects "[rub] against humans in a memorable way" (Freeman, Nienass, and Daniell 2016, 4-5). This view maintains that memory is dynamic and that its externalization does not necessarily lead to its decay. To the contrary, by paying attention to the interaction between humans and objects, and the unpredictable ways objects can participate in memory and forgetting, the line between internal and external memory is blurred. Jacques Derrida $(1981,1996)$ makes the related point that memory, whether externalized or internalized, is always a kind of writing, the meaning of which is beyond the 
subject's control. Rather than see this lack of control as a problem, Derrida contends that this interplay between memory and forgetting is a defining characteristic of fluid, dynamic subjectivity; to follow this line of thinking is to work against a view of forgetting as something that should be solely guarded against.

Throughout these perspectives lies a common question: how does externalization affect the interplay between memory and forgetting? What does it enable or disallow? In the view of memory as a retrievable, static, external container often lies the hope that memory can be managed. A stagnant memory does not threaten in the same way as the flood of dynamic sensation and unpredictable flows of information associated with individual memory. The concern about memory is also, therefore, a concern about forgetting: on the one hand, that the externalization will increase forgetting (insofar as the knowledge is no longer located "in us," so to speak); on the other hand, that the externalization will prohibit forgetting (insofar as memory's existence outside of us may take on an unpredictable life of its own). I turn now to bring this set of questions about the implications of externalized memory into conversation with the question of gender.

In recent years, there has been more attention paid to the role that state institutions play in administering gender (e.g., Currah and Moore 2009; Namaste 2005; Salamon 2010; Spade 2011). This shift in focus takes on increased urgency given the current clash in the US between the increased visibility of trans issues and the ongoing and intensifying violence against trans and gender nonconforming people. The cultural conversation around people who move away from the gender they are assigned at birth is arguably changing. However, the disproportionate violence faced by trans and gender nonconforming people in the US shows that there is an ongoing need to understand how and why an assignment of gender is enforced. Focusing on the state administration of gender requires us to pay particular attention to the effects of the initial assignment of gender, in the form of sex, at birth.

If we think about this initial gender assignment as an externalized memory, how is this memory created and preserved? What is at stake in the state preservation of a particular memory of the body (the body stamped at one point with $\mathrm{M}$ or $\mathrm{F}$ ) in various knowledge-gathering structures? Do such memories ensure the promises of bodies to function in particular ways? How does the externalized archiving of gender impact the way gender is lived? In a Nietzschean sense, I move now to trace the "burn" between individuals and the externalized memory of gender. Foregrounding the question of externalized memory expands what is at stake in thinking about gender as memory. I use the specific language of externalization to emphasize that the institutional forces that "burn memories in" are also invested in preserving memories of gender outside the body. In other words, the externalized memories I analyze here do not necessarily have to 
originate from an individual's (internal) memory, but rather indicate more broadly the institutional procedures by which "reminders" can operate at some remove from the individual, internal level. I explore the contours of this externalization of gender through two examples: identity documentation and sex-segregated institutions. I then close by exploring what resistant forgetting looks like at the level of externalized memory.

\section{Identity Documents}

Identity documentation poses a host of problems for trans and gender nonconforming people. Problems may occur due to the perception of a mismatch between an individual and an identity marker or even across institutions, such as when the DMV and the Social Security office possess conflicting gender designations (Meadow 2010; Spade 2003, 2011). ${ }^{8}$ Despite evidence that there is no simple legal or medical definition of gender or sex (Fausto-Sterling 2000; Greenberg 2012), state institutions continue to deploy rigid classification schemes. ${ }^{9}$ These schemes deploy rigidity as overcompensation for an actual lack of consensus, leading to a situation in which requirements for gender marker reclassification can vary widely not only between cities and across states but also across types of documentation, including birth certificates, social security cards, passports, state ID, and driver's licenses. These disparities may lead to having a driver's license that has one gender marker and a passport that has another, or being unable (due to cost and/or the required medical intervention) to have a changed marker at all.

The effects of being illegible within a particular classification system are intensified by one's location in intermeshed systems of power such as race, class, nationality, and ability, all of which will decrease or increase (depending on one's relative privilege in that system) the likelihood of being able to buy a way out of the system or bypass situations where identity documents are demanded. As one result of this interplay between a lack of consensus and the countervailing certainty that it must be possible to legislate a sexed body, identity documentation remains a source of harm. Richard Juang (2006) has emphasized the harmful effects of this failure of state recognition for transgender people, while others theorize sex as a matter of state allocation (Salamon 2010) and question the degree to which state recognition should be the goal of trans politics (Spade 2011). Regardless of one's position on the

\footnotetext{
8 In addition to state administrative systems, scholarship in trans studies is also beginning to look at the gendered contours of identity data in private sectors such as credit reporting (see Mackenzie 2017) to which I will turn below.

${ }^{9}$ As is apparent in the recent state "bathroom bills" in the US, these debates often rely on the language of biological sex. Given that what is at stake in this deployment of biological sex is control over gender, and the assumption of a system in which sex is gendered, I use the terms interchangeably here.
} 
goal of state recognition, however, it is clear that this conflict between one's "lived and documented gender" (Mock 2014, 144) has serious repercussions.

Thinking about the identity document through the lens of externalized memory has the advantage of foregrounding the role of time in debates around gender markers. For example, a repeated concern in these debates is the length of time an identity must be in place for a change of gender marker to be granted. The emphasis placed on gender assignment at birth translates to a normative expectation of "born this way" identity narratives as key to gaining legitimacy in the eyes of state institutions (Draz 2017). The framework of externalized memory draws attention to the institutional processes through which memories are made and preserved over time. Nietzsche's "burning in" of memories becomes a "burning out," as these identity documents preserve past gender assignments and remain a source of cisgender privilege.

In the case of identity documents, locating the memory-constituting punishment requires listening to those for whom such paperwork burns. While for many people such documents are barely noticeable (a mundane matter of paperwork), the memory is sufficiently punishing for others. Regardless of how someone is living, or how others affirm their lived gender, the past assignment preserved at this level can resist forgetting. The documentation too easily serves as a reminder; this memory, in turn, is used to either support or contradict the present. For those who are privileged by current arrangements, for whom the memory is more or less "correct," these systems of classification do not feel punishing. To the contrary, they feel quite boring. They are a matter of paperwork. However, the largest survey to date of trans people in the US found that only 11 percent of respondents had their preferred name and gender on all IDs and records, while 67 percent did not have an ID or record with the gender they preferred. A third of respondents reported harassment as a result. One respondent said, "Even after paying for proper identification to be issued, [the DMV] refused to send the identification because my female photo didn't match $m y$ ' $M$ ' gender marker," while others expressed the "disheartening, dysphoria-inducing, and kind of dehumanizing" effects of not being able to change documents at all or of having mismatched documents as a result of the state's refusal to change gender markers on birth certificates (James et al. 2016; see also Grant et al. 2011). For those who experience this disconnect between lived and documented gender, the "reminder" of the document and the persistence of a past assignment preserved therein can certainly burn.

\section{Sex-Segregated Bathrooms}

In addition to identity documentation, daily life also involves moving through architectural spaces designed around the presupposition of biological sex (and/as 
gender) as a division between male and female bodies. ${ }^{10}$ From locker rooms and schools to bathrooms and prisons, these sex-segregated institutions offer another example of gender as externalized memory. What do these structures remember about bodies? How do their reminders work on the bodies that move through them?

Take the example of sex-segregated bathrooms. In Queering Bathrooms, Sheila Cavanagh (2010) reports on a number of interviews she conducted with people who have experienced conflict while navigating bathrooms. A recurring theme in the interviews is how trans and/or gender nonconforming people are repeatedly read as "'out of place' in the gender-normative landscape of the bathroom, as anomalous beings" (63). While many of the interviewees emphasize the violent "look" of the other-a look that often exercises varying combinations of voyeurism, disgust, anxiety, and hostility-it is also the case that the architecture undergirds the validity of these social interactions, or the feeling of being "out of place." The very design of sex-segregated restrooms affirms the naturalness of the sex/gender system, a system that is, in turn, policed by those who feel enabled by its architectural embeddedness (Gersheson and Penner 2009; Kogan 2007; More 2008). A normative gender order is secured not only through this work of dividing space, but also by incorporating reminders of how the space should be used.

The justificatory power granted to bathroom signs illustrates this enabling work of architecture (Abel 2010; Nirta 2014). Using these signs is a crucial part of the memory work involved in navigating sex-segregated bathrooms. This memory work often involves a tripartite reading of the sign, self, and others; in this regard, Cavanagh notes that many trans and gender nonconforming interviewees emphasized that cis people often first read themselves as "out of place" when they encounter someone "unexpected" in the restroom. A number of interviewees report witnessing people choose which restroom to use based on their reading of the gender of the person coming in or out of the space (reading the other as sign), and then occasionally doubting whether they are in the right place depending on that reading. Often, however, the person will then check the door sign, exhibiting an intriguing amount of self-doubt about the extent to which one is supposed to adhere to the sign on the door or the other people in the bathroom. The process

${ }^{10}$ As with identity documentation, it is also the case that the more vulnerable you are within multiple systems of oppression, the more likely you are to move through additional sex-segregated institutions such as homeless shelters and prisons. In the case of bathrooms, for example, your class status may make it less likely that you will need to access public restrooms regularly, given that you may have easier access to private restrooms (whether in the home or in a place of business where a single stall restroom is available upon making a purchase). 
here follows a pattern: who are you? Am I in the right place? Am I that sign? Are you that sign? The potential disorientation is usually eased by the memory work of the sign, a sign that can be trusted to remember what otherwise we might all be more productively confused about.

The externalized memory of the sign enables a normative forgetting of the complexity of bathrooms and identification. Nietzsche also directs us to look for the 'burn' of this memory-making; in the space of the restroom, the burn of the sign indicates this memory work. The burning stare of the other indicates a memory that is being supported by this space. However, the reminders only burn for those who have failed, in some way, to allow this memory-making to go unnoticed. The view of identity underpinning these encounters is especially apparent in the recent debates in state legislatures around the so-called bathroom bills, wherein it is the past self, assigned at birth, who is supposed to use the restroom. The lived self is taken out of the equation. The navigation of this gendered space is thus designed to make one feel the reminder of this past assignment through its tension or acquiescence with one's present gender. The space is designed to remind inhabitants of the success or failure to match up to this past assignment. While the design of the sex-segregated restroom perpetuates the idea that knowing which one to use is an obvious and natural fact, the energy expended in policing both the space and oneself tells a different story.

Cavanagh (2010) describes the bathroom as a place of forgetting, of burying cultural logics and structures: "The bathroom is a repository for the societal unconscious: all that Western modernity forgets, disavows, and casts asunder in polite discourse" (29). In turn, her critical response can be understood as the work of remembering everything that is forgotten in the cultural function of the bathroom. I am arguing, however, that the bathroom is also a site of intense memory. Moving in and out of these spaces involves being reminded in a number of ways of what otherwise seems more at risk of resistant forgetting. It is a place where sex/gender in particular is remembered as architecture. We must, in turn, learn how to creatively forget this memory, or how to cultivate a resistant forgetting. In closing, I turn now to the question of what this resistant forgetfulness looks like at the level of externalized memory.

\section{Resistant Forgetting}

In the second of Nietzsche's (1997) Untimely Meditations, he questions the degree of forgetting that is necessary for the health of an individual or culture. The failure to forget is a "historical sickness" (120), a sickness contracted from being so tied up in the past that its repetition becomes a compulsion. As an antidote, the "art and power of forgetting" (120) promises to balance the historical and the 
unhistorical. In the language of Nietzsche's (1989) Genealogy of Morals, this is the kind of forgetting that "digests" and clears room.

Forgetting is not endorsed here as an abstract good. To the contrary, it is a specific tool wielded against an overdetermined (and overdetermining) past. Nietzsche's discussion of monumental history clarifies this point by explicitly marking a negative use of forgetting; in this mode of relating to history, the past is surveyed for its imitability or its worthiness of being monumentalized. To relate to the past in this monumentalizing way, so much has to be forgotten: "the past itself suffers harm: whole segments of it are forgotten, despised, and flow away in an uninterrupted colourless flood, and only individual embellished facts rise out of it like islands" (Nietzsche 1997, 70). Forgetting is negatively cast here as a strategic way to close the potential forces at work in the present; in other words, forgetting can be used to retroactively fit the past to the narrative needs of the present. In the framework of gender as internalized memory outlined above, this normalizing forgetting might involve, for example, the erasure of the work that goes into the habitually gendered body.

There is also, however, a resistant forgetting that rejects what has been "burnt in" in order to clear room for other relationships to the present. In Nietzsche's (1997) Untimely Meditations, this forgetting is involved in the critical mode of history: "If he [sic] is to live, man must possess and from time to time employ the strength to break up and dissolve a part of the past" (76). Here, forgetting represents the possibility of dissolving a calcified present. What if we took a cue from Nietzsche and saw the movement away from assigned genders as a sign of creative forgetfulness? What, then, stands in the way of these creative acts of forgetting? In considering gender as internalized memory, such resistant forgetting includes acting otherwise, or failing to remember what is expected. At the level of the individual, this may involve remembering the work that has gone into the habitual body in order to forget the expected repetition.

The shift to externalized memory complicates the question of resistant forgetting. What does resistant forgetting look like when gender, as memory, has been "burnt outside" the body, as in the examples of identity documents and sexsegregated institutions? First, I suggest that this shift involves attending to the consequences of a mismatch between one's lived and documented gender. It is crucial to situate this disconnect as a potential form of resistance to the preservation of an externalized memory while also attending to the harmful consequences of the preservation of gender at the level of the state. Resistant forgetting therefore involves thinking differently not only about how and why we participate in mundane, everyday acts of identity documentation but also about the kinds of punishments with which this memory-making is intertwined. 
In his work on gender markers and privatized credit reporting, Lars Mackenzie (2017) writes that "outdated data stick, maintaining a connection between a past and present identity and drawing a trans history into focus" (46, emphasis added). Data inconsistencies - or the "haunting" of past data (46) - caused by a change in name can cause trans people to become illegible to credit reporting systems, leading to long-lasting negative effects in areas such as employment and housing. When both administrative and consumer reporting systems expect an identity that is unchanging, the attempt to link a new legal identity to past data is thwarted by the persistence of that outdated data (the data that "sticks"). ${ }^{11}$ This is what Mackenzie refers to as the "afterlife" of identification data. Forgetting retains its doubled meaning here. On the one hand, it is tempting to say that the massive amount of information collected by big data surveillance is, in an important sense, forgotten. Certainly, much of it will never see the light of day. As a normalized forgetting, however, the massive amount of data does not simply disappear but rather threatens to reemerge as a memory that "burns" when the normative assumptions of identity are challenged in the present.

It is by taking advantage of this accumulation of externalized memory, however, that strategies of resistant forgetting also emerge. Mackenzie writes:

While the disconnected yet interrelated processes that go into producing a credit report are a bureaucratic nightmare for some, . . . the materiality of the bureaucracy may work in favor of illegible subjects at certain moments, disrupting the presumed omnipotent power of data systems to tell the truth about a person's identity. Trans people take advantage of the confusing and chaotic processes of data surveillance over their bodies, and the assertion that institutions must have the final word on which data are produced about them. (58)

Examples of this resistance include convincing data entry clerks that the gender marker on their IDs is clearly an error, claiming that SSNs must have been mixed up with a sibling, or simply asking a data entry clerk to change the record (56-58). The same inconsistencies that cause harm become potential sources of resistance. Affirming the actual dynamism of externalized memories becomes one way of resisting the harm of static and unmoving memories. Furthermore, such struggles are not only individual matters, but must be part of larger efforts to change the identity narratives expected and embodied by these data structures.

${ }^{11}$ The normative expectation that identity will remain unchanging over time may also lend force to the desire to narrate gender transition in terms of fundamental change. For a critical account of this narrative, see Billingsley 2015. 
Moving from identification data to the structures of sex-segregated bathrooms further complicates the question of what it means to forget an externalized memory. In the space of the bathroom, resistant forgetting may involve failing to engage in expected ways with architectural gender reminders. As we move through the space of the bathroom, paying attention to what has been made habitual-through normalized forgetting-has the potential to rewrite the repetitive scripts witnessed in Cavanagh's interviews, especially in terms of the unthinking reliance on a stable reading of self, other, and sign-as-arbiter.

Resistant forgetting may also be practiced at the level of architecture. In Nietzsche's (1989) defense of forgetting in Genealogy, forgetfulness allows one to "close the doors and windows of consciousness for a time" (57). Here, consciousness is figured as internal architecture; forgetting therefore operates metaphorically as a shutting of doors and windows. By tracing the externalization of memory, however, we also come to see the inverse: when architecture serves as consciousness, or as memory, forgetfulness must disrupt space in more literal ways. In this regard, consider universities that have refused to ontologize gender in the form of sexsegregated bathroom signs. As the result of student-led efforts to make campus bathrooms exclusively gender neutral, Hampshire College relabeled existing bathrooms (single and multi-stall) as "Gender Neutral Restroom," "Restroom with Urinals," or "Restroom without Urinals" (Pitcher and Zurn, forthcoming; Pryor 2017, 132). This rewriting of signs counteracts the normalizing memory work of sexsegregated signs with a resistant forgetting -in this case, such forgetting involves disrupting the reminders embedded in bathroom business as usual. It is also worth noting in this regard that an intermediary stage of signage at Hampshire relied on the language of "Self-Identified Men" and "Self-Identified Women"; when read through a Nietzschean framework of memory and forgetting, this signage arguably fails to adequately disrupt the normalizing memory work of the bathroom due to its continued reliance on familiar categories of male and female. While the effects of the most recent sign decision and this kind of architectural forgetting in general are far from predictable, such initiatives offer a way of thinking about what it means to make a bathroom forget. Beyond this specific example, the challenges faced more broadly by efforts to implement gender neutral bathrooms speak to the intense investment in the bathroom as an externalized memory of the normative body.

From another angle, Lucas Crawford (2014) argues that changing signs is not enough to disrupt the gendered space of the bathroom. While many of the arguments against gender neutral bathrooms fail to stand up to logical examination (Overall 2007), Crawford emphasizes that the demand for privacy and norms around hygiene are embodied by the architecture of the restroom in ways that resist rational critique. To take one example, the gendered space of the bathroom is also deeply racialized, connected as modern restrooms are to histories of public health 
and colonial anxiety. Crawford $(2014,634)$ concludes that "if washroom fears are ingrained in bodily habits at a different register than thoughtful rationality, then such fears will not respond to education campaigns or policy alone." The multilayered nature of the issues at stake in the bathroom leads Crawford to disagree that implementing gender-neutral space is enough to "neutralize" the bathroom. What does it mean, for example, that the "urinal" referent remains in the signs at Hampshire College? Is this language a way of preserving a memory of the body, and therefore of expected gender? Rather than resolving the question of whether rewriting bathroom signs in any particular way is sufficient, I suggest the Nietzschean framework of memory, especially when expanded to the question of externalized memory, allows a way to navigate these questions with a focus on both the importance and complexity of engaging in resistant forgetting.

\section{Conclusion: Clearing Room}

I have offered two examples of externalized memory and resistant forgetting through identity documents and sex-segregated institutions. In both cases, gender is being preserved outside the body. Taking seriously this externalization of gender has several implications that allow us to rethink Nietzsche's account of memory and forgetting in a contemporary frame.

First, while social or interpersonal punishment may continue to burn gender into the body (and it certainly does), institutionally administered punishment is focused on burning a version of gender outside the body. At this level of power, punishment targets a mismatch between lived and documented gender or a mismatch between a person and an institution. These consequences range from not being able to access health care to being denied housing and employment. This kind of mismatch also causes intensified visibility and vulnerability in spaces such as airports, interactions with police, and seemingly mundane, everyday actions such as using the bathroom. The punishment here is importantly distinct. Its contours direct our attention to rates of incarceration, unemployment, partial employment, lack of social security, and so on. Such punishment is in some way removed from the body, even as it impacts bodily experience. By analyzing the impact of gender as an externalized memory, we grant new life to Nietzsche's questions about memory and forgetting. While the individual level remains important, disrupting such externalized memory requires different strategies. In other words, a focus on the internalization of gender does not offer a sufficient explanation of how gender operates as a memory today or of what resistant forgetting might entail at this externalized level.

Second, this shift to gender as externalized memory relates directly to recent conversations in feminist and queer theory around how to best understand a neoliberal embrace of nonconformity at the level of the individual (e.g. W. Brown 
2015; Duggan 2003; McWhorter 2012; Winnubst 2012, 2015). Many scholars and activists have questioned how to understand a shift in regimes of power from a focus on individual bodies to a focus on what Foucault calls security and population management. Given neoliberal claims to love difference and diversity - a love that allows the machine of capitalist, entrepreneurial subjectivity to have even more material to profit from-power can appear to have loosened its hold on the individual. As a result, there has been a struggle to understand an increased embrace of nonconformity and diversity that confounds longstanding feminist frameworks built around a fear of difference. The externalization of memory offers one way to understand how identity categories such as gender are being preserved along other levels of power, even as there is a claim to embrace diversity and nonconformity at the level of the individual.

In light of Nietzsche's interest in how the whole "bloody, bodily process" of instituting memory only comes to a "sort of end" with the internalization of consciousness, I have examined the externalization of this consciousness through the examples of identity documents and sex-segregated institutions. By separating a normalizing forgetting from a resistant forgetting, I have also made clearer the kind of memory work involved in each. Resistant forgetting requires resistant memory work; this work sifts through the institutional practices that legitimize particular identity arrangements at the expense of others. Knowing what has been "burnt in" is crucial for resistant forgetting; the past is loosened, rather than solidified, through this resistant memory work. As a result, other movements become thinkable in the present. Nietzsche $(1997,76)$ is clear that "it is not possible to wholly free oneself from this chain [of the past]." Something like complete forgetting, a blank slate, is not the goal. To simply regard oneself as free of the past is not the purpose; rather, the goal is to understand what one has inherited "so that our first nature withers away" (76). Creating a second nature, here, is then "an attempt to give oneself . . a past in which one would like to originate in opposition to that in which one did originate" (76). Resistant forgetting is not invested in erasure but in how to reopen the present; in Nietzsche's words, this is a forgetting that "clears room." As demonstrated by the example of architecture, it is through the realization that a space is remembering for you that resistant forgetting becomes possible; this occurs not in order to erase any trace of that past normalizing memory work but as a way of reopening the present.

Certainly, both forgetfulness and memory can be used in the name of the status quo. Forgetfulness can be used to absolve oneself of responsibility just as memory can be used to ensure that one controls the present and future. As theorists of colonialism have shown repeatedly, temporality is a crucial tool in struggles for power. Forgetting is too often wielded as an instrument of the powerful. Nietzsche, however, urges us to also see forgetting as a positive activity. 
Against the view of it as a passive and negative force, forgetting may be a creative and resistant act. We must in turn also be more creative about locating where and how we are being remembered.

\section{References}

Abel, Elizabeth. 2010. Signs of the Times: The Visual Politics of Jim Crow. Berkeley: University of California Press.

Ahmed, Sara. 2006. Queer Phenomenology: Orientations, Objects, Others. Durham, NC: Duke University Press.

- 2017. Living a Feminist Life. Durham, NC: Duke University Press.

Bartky, Sandra Lee. 1990. Femininity and Domination. New York: Routledge.

Billingsley, Amy. 2015. "Technology and Narratives of Continuity in Transgender Experiences." Feminist Philosophy Quarterly 1 (1). Article 6. doi:10.5206/fpq/2015.1.6.

Bowker, Geoffrey C. 2005. Memory Practices in the Sciences. Cambridge, MA: MIT Press.

Brown, Kristen. 2006. Nietzsche and Embodiment: Discerning Bodies and NonDualism. Albany: State University of New York Press.

Brown, Wendy. 2015. Undoing the Demos: Neoliberalism's Stealth Revolution. Cambridge, MA: MIT Press.

Butler, Judith. 1999. Gender Trouble: Feminism and the Subversion of Identity. New York: Routledge. 2008. Giving an Account of Oneself. New York: Fordham University Press.

Cavanagh, Sheila. 2010. Queering Bathrooms: Gender, Sexuality, and the Hygienic Imagination. Toronto: University of Toronto Press.

Ceglowski, Maciej. 2015. "Haunted by Data." YouTube video, 20:10. Posted by O’Reilly, Oct. 4, accessed July 11, 2017. https://www.youtube.com/watch?v=GAXLHM-1Psk.

Certeau, Michel de. 1984. The Practice of Everyday Life. Berkeley: University of California Press.

Crawford, Lucas Cassidy. 2014. "Derivative Plumbing: Redesigning Washrooms, Bodies, and Trans Affects in ds+r's Brasserie." Journal of Homosexuality 61 (5): 621-635.

Currah, Paisley, and Lisa Jean Moore. 2009. "'We Won't Know Who You Are': Contesting Sex Designations in New York City Birth Certificates." Hypatia 24 (3): 113-135.

Derrida, Jacques. 1981. Dissemination. Chicago: University of Chicago Press. 
1996. Archive Fever: A Freudian Impression. Chicago: University of Chicago Press.

Diprose, Rosalyn. 2002. Corporeal Generosity: On Giving with Nietzsche, MerleauPonty, and Levinas. Albany: State University of New York Press.

Draz, Marie. 2017. "Born This Way? Time and the Coloniality of Gender." Journal of Speculative Philosophy 31 (3): 372-384.

Duggan, Lisa. 2003. The Twilight of Equality? Neoliberalism, Cultural Politics, and the Attack on Democracy. Boston: Beacon Press.

Edelman, Lee. 2007. No Future Queer Theory and the Death Drive. Durham, NC: Duke University Press.

Fausto-Sterling, Anne. 2000. Sexing the Body: Gender Politics and the Construction of Sexuality. New York: Basic Books.

Forty, Adrian, and Susanne Küchler. 1999. The Art of Forgetting. New York: Bloomsbury.

Foucault, Michel. 1977. Discipline \& Punish. New York: Random House.

Freeman, Lindsey A., Benjamin Nienass, and Rachel Daniell. 2016. "Memory | Materiality | Sensuality." Memory Studies 9 (1): 3-12.

Gersheson, Olga, and Barbara Penner. 2009. Ladies and Gents: Public Toilets and Gender Philadelphia: Temple University Press.

Grant, Jaime M., Lisa Mottet, Justin Edward Tanis, Jack Harrison, Jody Herman, and Mara Keisling. 2011. Injustice at Every Turn: A Report of the National Transgender Discrimination Survey. Washington, DC: National Center for Transgender Equality.

Greenberg, Julie A. 2012. Intersexuality and the Law: Why Sex Matters. New York: New York University Press.

Grosz, Elizabeth. 1994. Volatile Bodies: Toward a Corporeal Feminism. Bloomington: Indiana University Press.

Halberstam, Jack. 2011. The Queer Art of Failure. Durham, NC: Duke University Press.

James, Sandy E., Jody L. Herman, Susan Rankin, Mara Keisling, Lisa Mottet, and Ma'ayan Anafi. 2016. The Report of the 2015 U.S. Transgender Survey. Washington, DC: National Center for Transgender Equality.

Juang, Richard M. 2006. "Transgendering the Politics of Recognition." In Transgender Rights, edited by Paisley Currah, Richard M. Juang, and Shannon Minter, 242-261. Minneapolis: University of Minnesota Press.

Kogan, Terry. 2007. "Sex-Separation in Public Restrooms: Law, Architecture, and Gender." Michigan Journal of Gender and Law 14 (1): 1-57.

Lugones, Marìa. 2003. Pilgrimages/Peregrinajes: Theorizing Coalition against Multiple Oppressions. Lanham, MD: Rowman \& Littlefield. 
Lupton, Deborah. 2013. "Swimming or Drowning in the Data Ocean? Thoughts on the Metaphors of Big Data." This Sociological Life (blog), Oct. 4. Accessed October 1, 2017. https://simplysociology.wordpress.com/2013/10/29/swimming-ordrowning-in-the-data-ocean-thoughts-on-the-metaphors-of-big-data/.

Mackenzie, Lars. 2017. "The Afterlife of Data Identity, Surveillance, and Capitalism in Trans Credit Reporting." TSQ: Transgender Studies Quarterly 4 (1): 45-60.

McWhorter, Ladelle. 2012. "Queer Economies." Foucault Studies 14:61-78.

Meadow, Tey. 2010. "'A ROSE is a ROSE': On Producing Legal Gender Classifications." Gender and Society 24 (6): 814-837.

Mock, Janet. 2014. Redefining Realness: My Path to Womanhood, Identity, Love \& So Much More. New York: Simon \& Schuster.

More, Alex. 2008. "Coming Out of the Water Closet: The Case against SexSegregated Bathrooms." Texas Journal of Women and the Law 17 (2): 297315.

Namaste, Viviane. 2005. Sex Change, Social Change: Reflections on Identity, Institutions, and Imperialism. Toronto: Women's Press.

Nietzsche, Friedrich. 1989. On the Genealogy of Morals. Translated by Walter Kaufman and R. J. Hollingdale. New York: Vintage Books.

_ 1997. Untimely Meditations. Translated by R. J. Hollingdale. Cambridge: Cambridge University Press.

Nirta, Caterina. 2014. "Trans Subjectivity and the Spatial Monolingualism of Public Toilets." Law and Critique 25 (3): 271-288.

Oliver, Kelly. 1995. Womanizing Nietzsche: Philosophy's Relation to the "Feminine." New York: Routledge.

Oliver, Kelly, and Marilyn Pearsall, eds. 1998. Feminist Interpretations of Friedrich Nietzsche. University Park: Pennsylvania State University Press.

Overall, Christine. 2007. "Public Toilets: Sex Segregation Revisited." Ethics \& the Environment 12 (2): 71-91.

Pitcher, Erich, and Perry Zurn. 2017. "The History of Trans* Activism and Trans* Inclusive Policies at Hampshire College." Unpublished Manuscript.

Pryor, Jaclyn. 2017. Time Slips: Queer Temporalities, Contemporary Performance, and the Hole of History. Evanston, IL: Northwestern University Press.

Salamon, Gayle. 2010. Assuming a Body: Transgender Theory and Rhetorics of Materiality. New York: Columbia University Press.

Spade, Dean. 2003. "Resisting Medicine, Re/Modeling Gender." Berkeley Women's Law Journal 18 (May): 15-37.

- 2011. Normal Life: Administrative Violence, Critical Trans Politics and the Limits of Law. Brooklyn: South End Press.

Stryker, Susan. 2008. Transgender History. Berkeley, CA: Seal Press. 
Winnubst, Shannon. 2012. "The Queer Thing about Neoliberal Pleasure: A Foucauldian Warning." Foucault Studies 14 (September): 79-97. doi:10.22439/fs.v0i14.3889.

_. 2015. Way Too Cool: Selling out Race and Ethics. New York: Columbia University Press.

Young, Iris Marion. 2005. On Female Body Experience: "Throwing Like a Girl" and Other Essays. New York: Oxford University Press.

MARIE DRAZ is Assistant Professor of Philosophy and Associate Director of the Institute for Ethics and Public Affairs at San Diego State University. Her research examines how ideas about sex and gender are maintained through state institutions. In her current work, she is exploring the relationship between this state administration of identity and theories of race, colonialism, and time. 